\title{
Selection of drought-tolerant rice varieties from the rice variety bank of Can Tho university
}

Tin Q. Huynh*, An V. Ngo, Loi H. Nguyen, \& Dien N. Huynh

Mekong Delta Development Research Institute, Can Tho University, Can Tho, Vietnam

\section{ARTICLE INFO \\ Research Paper \\ Received: September 05, 2018 \\ Revised: December 22, 2018 \\ Accepted: January 02, 2019}

Keywords

Drought tolerance

Marker

Rice varieties

${ }^{*}$ Corresponding author

Huynh Quang Tin

Email: hqtin@ctu.edu.vn

\section{ABSTRACT}

Drought has been a big problem and damaged seriously to rice cultivation and production in Vietnam and the Mekong Delta region; evaluating drought tolerance of rice is a major objective for the rice improvement programmes in Can Tho University. Fifty-two collected rice varieties including resistant and susceptible control varieties were screened for water stress under the artificial drought condition. Marker RM223 was used to identify the drought tolerance genotypes for some selected varieties with good and moderate tolerant scores. After 30 days of water stress, the results were 6 varieties of good tolerant, 8 varieties of moderate tolerance, 36 varieties of moderately susceptible and 2 varieties of susceptible to drought. Analyse of PCR showed that 10 varieties expressed the similar bands with the resistant control variety. Four varieties (LH8, MTL812, Lua Canh and VB1) with good tolerant to drought were recommended to use for genetic materials of rice breeding program and applying in alternative wetting and drying irrigation technique for rice cultivation.

Cited as: Huynh, T. Q., Ngo, A. V., Nguyen L. H., \& Huynh, D. N. (2019). Selection of droughttolerant rice varieties from the rice variety bank of Can Tho university. The Journal of Agriculture and Development 18(2), 65-70. 


\title{
Thanh lọc giống lúa chịu hạn từ Ngân hàng giống của Trường Đại học Cần Thơ
}

\author{
Huỳnh Quang Tín*, Ngô Vĩnh An, Nguyễn Hữu Lợi \& Huỳnh Như Điền \\ Viện Nghiên Cứu Phát Triển Đồng Bằng Sông Cửu Long, Trường Đại Học Cần Thơ, Cần Thơ
}

THÔNG TIN BÀI BÁO
Bài báo khoa học
Ngày nhận: 05/09/2018
Ngày chînh sưa: 22/12/2018
Ngày chấp nhận: 02/01/2019
Từ khóa
Chịu hạn
Dâu phân tử
Giống lúa
*Tác giả liên hệ
Huỳnh Quang Tín
Email: hqtin@ctu.edu.vn

\section{TÓM TẮT}

Khô hạn đã và đang là trở ngại đến sản xuất và và thất thu về sản lượng lúa ở Việt Nam và Đồng bằng sông Cửu Long (ĐBSCL). Việc thanh lọc, đánh giá giống lúa chống chịu hạn là mục tiêu quan trọng của chương trình cải thiện giống lúa tại Trường Đại Học Cần Thơ (ĐHCT). Năm mươi hai giống lúa được sưu tập (gồm giống chuẩn kháng và chuẩn nhiễm) đã được thử nghiệm trong điều kiện hạn nhân tạo. Những giống lúa có khả năng chịu hạn khá được chọn để tiếp tục đánh giá liên kết gen kháng bằng kỹ thuật điện di với marker R223. Kết quả đánh giá sau 30 ngày xử lý hạn có 6 giống chịu hạn tốt, 8 giống chịu hạn trung bình, 36 giống chịu hạn kém và 2 giống chịu hạn kém. Sản phẩm $\mathrm{PCR}$ cho thấy 10 giống có biểu hiện băng tương đồng với giống đối chứng kháng. Tổng hợp các kết quả đánh giá, chúng tôi chọn 4 giống (LH8, MTL812 Lúa cánh và VB1) chịu hạn tốt để khuyến cáo sử dụng cho chương trình lai tạo giống lúa mới và ứng dụng trong canh tác lúa với kỹ thuật tưới ngập khô xen kẽ.

\section{1. Đặt Vấn Đề}

Lúa là cây trồng lương thực quan trọng nhất cho người dân ở ĐBSCL. Với diện tích gieo trồng khoảng 4,2 triệu ha, nó đóng góp khoảng 24 triệu tấn lúa, chiếm $56 \%$ tổng sản lượng lúa cả nước (GSO, 2016). Thời gian gần đây, sự thay đổi khí hậu toàn cầu "sự gia tăng nhiệt dộ và thiếu hụt lượng mưa" tạo nên hoang mạc hóa, khô hạn và đất nhiễm mặn. Ở những vùng sản xuất nông nghiệp của Việt Nam, 240.215 ha lúa bị thiệt hại. Trong đó, các tỉnh ĐBSCL hơn 40.000 ha bị ảnh hưởng làm giảm năng suất và khoảng 25.900 ha đất trồng trọt đang bỏ trống không thể sử dụng (Nguyen, 2016). Hơn thế nữa, hạn hán là một hiện tượng phức tạp so với hầu hết các tác động từ môi trường như độ mặn, ngập nước và sâu bệnh (Nguyen \& Bui, 2008). Khô hạn có thể xảy ra tại bất kỳ thời điểm nào trong quá trình sản xuất cây trồng và trong bất kỳ khoảng thời gian nào, ảnh hưởng đến một loạt các quá trình sinh lý, sinh hóa và phân tử của cây lúa (Manickavelu \& ctv., 2006) vì thế cây lúa thuộc nhóm nhạy cảm với các yếu tố môi trường tác động (Le \&
Tran, 2013). Sự ảnh hưởng của khô hạn về thời gian khô hạn và cường độ đã đặt ra một thách thức lớn và là mục tiêu hàng đầu đối với các nhà khoa học trong chọn giống lúa chịu hạn trên thế giới (Manickavelu \& ctv., 2006; Nguyen \& Bui, 2008). Vì vậy, "Thanh lọc giống lúa chịu hạn từ Ngân hàng giống của Trường Đại học Cần Thơ" được thực hiện nhằm tìm ra những giống có khả năng chống chịu hạn tốt làm nguồn vật liệu di truyền phục vụ công tác cải thiện giống lúa mới cho ĐBSCL trong tương lai.

\section{Vật Liệu và Phương Pháp Nghiên Cứu}

\subsection{Vật liệu}

Bộ giống thử nghiệm gồm 52 giống lúa được sưu tập ở nhiều địa phương khác nhau và được lưu trữ tại Ngân hàng giống lúa của Viện Nghiên cứu Phát triển ĐBSCL, Trường Đại học Cần Thơ (Bảng 1).

Các dụng cụ cần thiết như khay nhựa, rây đất, khoan mẫu đất, máy sấy mẫu đất và nhà lưới được sử dụng cho thí nghiệm. 
Bảng 1. Các giống lúa đã sử dụng để thanh lọc chịu hạn từ Ngân hàng giống lúa của Trường Đại học Cần Thơ

\begin{tabular}{llll}
\hline TT Tên giống $^{1}$ & TT Tên giống \\
\hline 1 & ND1 & 27 & Nếp Fulngam* \\
2 & LV6 & 28 & Lúa Cánh* \\
3 & TC7 & 29 & Mali Thái \\
4 & Ba ĩe & 30 & Điễu Ju Blít \\
5 & MTL250 & 31 & Ba Chăm \\
6 & Bakơđeh & 32 & Ba Cong Vàng \\
7 & Bla buông & 33 & Ba Coong \\
8 & Dai Ngo & 34 & Ba Plăn \\
9 & Làng Mèo & 35 & Ba Tranh \\
10 & NV16 & 36 & Thái Hồng* (kháng) \\
11 & Lúa Ngọt & 37 & Brônh \\
12 & Nếp Đỏ (Thái) & 38 & DaiKa Anheng \\
13 & Anhẽ* & 39 & Dai Kalit \\
14 & Ba Jirui & 40 & Dai Pơng \\
15 & Ba Lang & 41 & LH14 \\
16 & Ba Pơ Mỡn & 42 & Nếp Thơm \\
17 & Ba Quoang & 43 & IR20* (nhiễm) \\
18 & Blang* & 44 & Thái Trăng \\
19 & Cbr* & 45 & Nàng Kao \\
20 & Chơ Bra & 46 & KeKo* \\
21 & Cher & 47 & ML202* \\
22 & Cit Noal & 48 & ND3* \\
23 & Cúc Quang* & 49 & LH9 \\
24 & VB1* & 50 & ND4 \\
25 & LH8* & 51 & ND5 \\
26 & MTL812* & 52 & LH13* \\
\hline
\end{tabular}

${ }^{1}$ Những giống có dấu (*) có khả năng chống chịu hạn và được chọn cho phân tích gen kháng.

\subsection{Thanh lọc khả năng chống chịu hạn của các giống lúa trong điều kiện Nhà lưới}

Bố trí thí nghiệm: Các giống lúa được bố trí hoàn toàn ngẫu nhiên với 03 lần lặp lại, giống đối chứng Thái Hồng (chuẩn kháng) và IR20 (chuẩn nhiễm).

Chuẩn bị đất: Đất được phơi trong mát 4 tuần, rây nhuyễn, cho vào từng khay nhựa với trọng lượng đất bằng nhau (40 kg/khay), độ dày đất $20 \mathrm{~cm}$. Rạch hàng với khoảng cách $8 \mathrm{~cm}$, chiều dài hàng $10 \mathrm{~cm}$. Cung cấp nước (14 lít/khay) đạt ẩm độ bảo hòa cho đất trong khay, đánh số thứ tự và đặt tất cả các khay vào nhà lưới có máy che.

Chuẩn bị gieo: Hạt giống được gieo nảy mầm trong đĩa petri. Gieo mỗi giống 10 hạt đã nảy mầm, 3 lần lặp lại, phủ đất mịn lên trên. Sau đó
5 - 6 ngày tỉa lại còn 10 cây có sức sống tốt và đồng đều.

Phương pháp lấy ẩm độ đất: Dùng ống khoan thép có đường kính $3,5 \mathrm{~cm}$, khoan ba điểm ngẫu nhiên trên khay đất thí nghiệm ở độ sâu $10 \mathrm{~cm}$, mẫu thu được cho vào bọc kín, sau đó, mẫu nhanh chóng chuyển về phòng thí nghiệm để tiến hành phân tích ẩm độ. Phân tích ẩm độ đất dựa trên sự chênh lệch về khối lượng giữa mẫu đất trước khi sấy và mẫu đất sau sấy khô kiệt ở nhiệt độ $105^{0} \mathrm{C}$ (sấy khô đến khối lượng không đổi) để tính ẩm độ.

Công thức tính:

$$
\theta_{\mathrm{m}}=\frac{\mathrm{M}_{\mathrm{w}}}{\mathrm{M}_{\mathrm{s}}} ; \mathrm{P}_{\mathrm{m}}(\%)=\theta_{\mathrm{m}} \times 100
$$

Trong đó:

$\theta_{\mathrm{m}}$ : Hàm lượng nước khối lượng $(\mathrm{g} / \mathrm{g})$.

Pm: Phần trăm khối lượng nước $(\%)$.

$\mathrm{M}_{\mathrm{w}}$ : Khối lượng nước trong mẫu đất $(\mathrm{g})$.

$\mathrm{M}_{\mathrm{S}}$ : Khối lượng mẫu đất khô kiệt $(\mathrm{g})$.

Đánh giá mức độ chống chịu hạn: Xử lý khô hạn (ngưng cung cấp nước) lúc 14 ngày sau khi gieo và đánh giá tính chịu hạn của cây lúa theo các giai đoạn lấy ẩm độ đất tương ứng (ngày cắt nước và tiếp tục 4 ngày/lần đến khi giống chuẩn nhiễm khô lá cấp 7 - 9), theo thang đánh giá IRRI (2014) (Bảng 2).

Bảng 2. Bảng đánh giá mức độ khô lá của cây lúa

\begin{tabular}{cl}
\hline Cấp & Biểu hiện của cây lúa \\
\hline 0 & Cây và lá chưa bị ảnh hưởng \\
1 & Đầu lá hơi khô \\
3 & Từ đầu đến $1 / 4$ lá của tổng số lá bị khô \\
5 & $1 / 2$ của tổng số lá bị khô \\
7 & $2 / 3$ số lá bị khô \\
9 & Tất cả các cây đều chết \\
\hline
\end{tabular}

Nguồn: (IRRI, 2014).

\subsection{Khảo sát sự liên kết giữa marker phân tử và gen chịu hạn}

Mẫu lá lúa được thu thập tại thời điểm cây lúa 20 ngày tuổi để ly trích DNA. Tiến trình ly trích DNA được áp dụng quy trình CTAB (Rogers \& Bendich, 1988). Thực hiện phản ứng $\mathrm{PCR}$ với một cặp mồi RM223, trình tự mồi ngược và xuôi theo Kibria \& ctv. (2009) như sau:

RM223: 5' GAGTGAGCTTGGGCTGAAAC 3 , 

3

\subsection{Xử lý số liệu}

Số liệu thí nghiệm được xử lý bằng phần mềm Excel, phân tích thống kê bằng chương trình SPSS Version 20 và đánh giá qua băng hình từ sản phẩm PCR so với đối chứng.

\section{Kết Quả và Thảo Luận}

\section{1. Đánh giá khả năng chịu hạn của các giống lúa dựa trên đáp ứng sinh lý}

\subsection{1. Đánh giá tính chống chịu hạn của các giống lúa thí nghiệm trong nhà lưởi}

Kết quả đánh giá khả năng chịu hạn trong nhà lưới của các giống lúa qua các thời điểm sau xử lý hạn và đánh giá phản ứng của cây lúa với điều kiện thiếu nước thể hiện qua hiện tượng cuốn lá và khô lá. Thí nghiệm này đánh giá cấp khô lá cho khả năng chịu hạn như sau: 18 ngày sau khi xử lý hạn (NSXLH) đã ghi nhận một số giống lúa bắt đầu có lá bị khô (hơn $1 / 4$ của tồng số lá) có 47 giống chịu hạn tốt và 5 giống lúa chịu hạn trung bình (Bảng 3); đến 26 NSXLH có 13 giống lúa chịu hạn tốt, và 30 ngày có 6 giống lúa chịu hạn tốt, 2 giống chết do mẫn cảm với hạn. So với giống đối chứng, các giống chống chịu hạn tốt là VB1, LH8, MTL812 và Lúa cánh; giống chịu hạn trung bình là Ba Pơ Mỡn, Cúc Quang và ND3. Phần lớn các giống lúa sưu tập ở vùng Tây Nguyên có tính chịu hạn trung bình, kết quả này phù hợp với các báo cáo rằng tính trạng chịu hạn trung bình của một số giống lúa rẫy sau thời gian bị hạn một tháng (Nguyen \& Huynh, 1999; Ong \& ctv., 2004).

\subsubsection{Tương quan giữa ẩm độ đất và mức độ chịu hạn của các giống lúa}

Ẩm độ đất tương đối là một yếu tố ảnh hưởng trực tiếp và rõ rệt đến cây trồng, nhất là những loại cây ngắn ngày như cây lúa (Ong \& ctv., 2004). Nghiên cứu về mối tương quan giữa ẩm độ đất và nhu cầu nước của cây lúa là về khả năng đáp ứng của cây lúa với sự thiếu hụt nước. Kết quả thí nghiệm chỉ ra rằng có sự tương quan rất chặt giữa ẩm độ đất và khả năng chịu hạn của các giống lúa $\left(\mathrm{R}^{2}=73,4 \%\right)$. Phương trình về sự tương quan giữa ẩm độ đất và cấp độ khô lá (y $=4,87-0,15 \mathrm{x})$ cho thấy khi giá trị ẩm độ đất $(\mathrm{x})$ 
giảm $1 \%$ đơn vị thì cấp độ khô lá (chịu hạn) của các giống lúa thí nghiệm tăng 0,15 - nghĩa là khả năng chịu hạn của giống sẽ giảm đi (Hình 1).

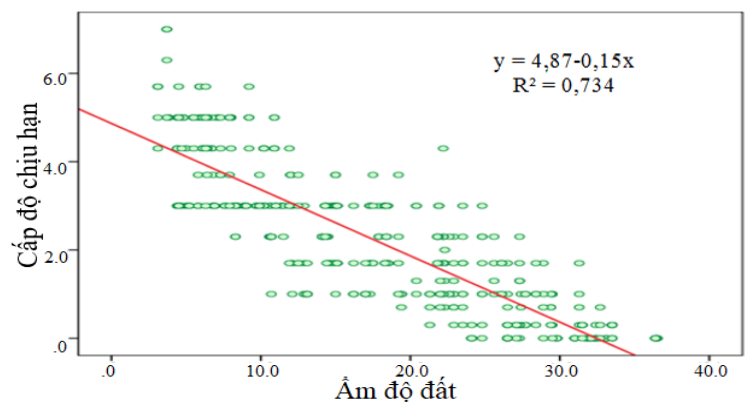

Hình 1. Tương quan giữa cấp khô lá và ẩm độ đất thí nghiệm qua thời gian xử lý hạn.

Đến thời điểm 30 NSKXL, $2 / 3$ số lá của giống chuẩn nhiễm IR20 bị khô, khi đó ẩm độ đất trung bình là $3,7 \%$, cấp chịu hạn của các giống lúa là 4,3 (Hình 1) thể hiện bằng cấp khô lá (chịu hạn). Trong nghiên cứu này các giống VB1, LH8, MTL812, Lúa Cánh có cấp khô lá thấp nhất. Chỉ số cuốn lá, khô lá và nhiệt độ có mối tương quan âm với ẩm độ đất (Kumar \& ctv., 2005). Nghiên cứu cũng cho thấy cấp độ khô lá khác nhau của các giống lúa thể hiện mối tương quan với mức độ đáp ứng của giống lúa với mức độ gia tăng của sự thiếu hụt nước. Kết quả này minh chứng thêm kết quả nghiên cứu đã công bố của Sumontip \& Prapaporn (2013) và Ong \& ctv. (2004), với giống kháng thì chỉ thị khả năng duy trì tiềm năng nước trong lá cao, Munns (2002) cho biết sự giảm tiềm năng nước trong lá khi nước trong đất trở nên thiếu hụt, qua đó sự hấp thụ nước kém hướng tới giảm sự trương nước của lá.

\section{4. Đánh giá liên kết giữa marker phân tử và gen chống chịu hạn}

Kết quả đánh giá kiểu gen chịu hạn bằng marker RM223 (Hình 2) cho thấy có sự khác nhau giữa đối chứng kháng (giống Thái Hồng) và đối chứng nhiễm IR20. Điều này cho thấy RM223 là marker đa hình có liên kết với gen chịu hạn, RM 223 là marker nằm trên nhiễm sắc thể số 8 của lúa, marker này liên kết với tính trạng chống chịu hạn với băng hình thể hiện tính kháng là 190 bp (có 10 giống) và băng thể hiện tính mẫn cảm hạn là 175 bp.

Kết quả (Hình 2) cho thấy các giống VB1, Lúa Cánh, MTL812, Nếp Fulngam, LH8, ML202,
LH13, Blang, KeKo và A Nhẽ có băng (190bp) trùng với đối chứng kháng (giống Thái Hồng). Các giống Cúc Quang, ND3 và Cbr có băng (175 bp) trùng với đối chứng nhiễm (IR20). Chỉ thị RM223 đã cho băng hình khác nhau giữa các giống và các giống có sự liên kết với tính chịu hạn của chỉ thị phân tử RM223 tương ứng với chỉ thị của giống chuẩn kháng. Trong nghiên cứu này chỉ áp dụng chỉ thị RM223 chưa có phân tích về đa hình của các chỉ thị khác với tính trạng mục tiêu. Vì vậy, nghiên cứu bước đầu ghi nhận các giống có biểu thị tính kháng hạn và cần có những nghiên cứu tiếp theo. Tuy vậy, áp dụng đánh dấu phân tử để xác định tính liên kết chống chịu hạn đang là công cụ hữu ích trong chọn giống có hỗ trợ dấu phân tử - MAS theo Kumar \& ctv. (2005) sẽ giúp tiến trình đánh giá được nhanh và chính xác hơn.

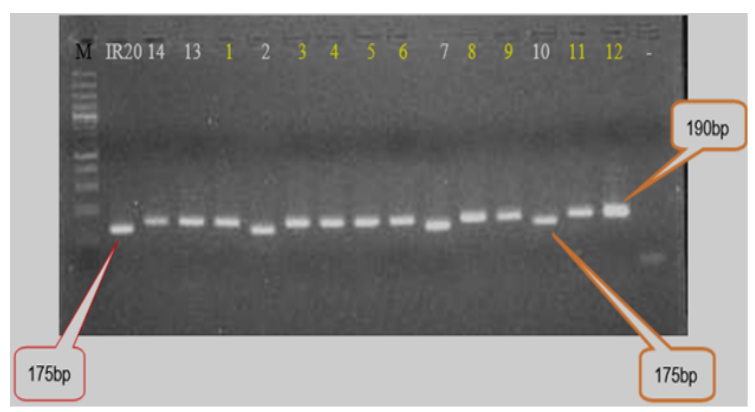

Hình 2. Kết quả điện di sản phẩm PCR của marker RM223.

M: marker, IR20 (ĐC nhiễm); 1: VB1; 2: Cúc Quang; 3: Lúa Cánh; 4: MTL812; 5: Nếp Lào Fulngam; 6: LH8; 7: ND3; 8: ML202; 9: LH13; 10: Cbr; 11: Blang; 12: A Nhẽ; 13: Ke Ko; 14: Thái Hồng (ĐC kháng).

\section{Kết Luận}

Kết quả thí nghiệm thanh lọc đã tìm ra được các giống lúa có khả năng chịu hạn tốt tương đương giống đối chứng tại 30 ngày sau khi xử lý hạn là VB1, ND3, LH8, MTL812 Keko và Lúa cánh; RM223 có liên kết với gen chịu hạn của các giống VB1, Lúa Cánh, MTL812, Nếp Fulngam, LH8, ML202, LH13, Blang, và A Nhẽ có băng (190bp) trùng với đối chứng kháng (giống Thái Hồng).

Bốn giống LH8, MTL812, Lúa cánh, VB1 chống chịu hạn tốt được chọn để làm vật liệu tai tạo giống lúa mới và và khuyến cáo ứng dụng trong canh tác lúa với kỹ thuật tưới ngập khô xen kẽ và vùng khó khăn nước tưới. 


\section{Lời Cảm Ơn}

Nhóm tác giả đề tài nghiên cứu nầy chân thành cảm ơn đến Trường Đại Học Cần Thơ đã hỗ trợ kinh phí nghiên cứu qua đề tài khoa học công nghệ cấp cơ sở và sự nhiệt tình tham gia thực hiện của cán bộ Viện Nghiên Cứu Phát triển Đồng Bằng sông Cửu Long và sinh viên của Trường.

\section{Tài Liệu Tham Khảo (References)}

GSO (General Statistics Office of Vietnam). (2016). Agricultural, forestry and fishery statistics. Retrieved August 19, 2018, from https://www.gso.gov.vn/default.aspx?tabid=717.

Kibria, K., Nur, F., Begum, S. N., Islam, M. M., Paul, S. K., Rahman, K. S., \& Azam, S. M. M. (2009). Molecular marker based genetic diversity analysis in aromatic rice genotypes using ssr and rapd markers. Journal of Crop Production 4(1), 23-34.

Kumar, B., Gomez, S. M., Boopathi, N. M., Kumar, S. S., Kumaresan, D., Biji, K. R., Babu, B. K., Prasad, N. S. R., Shanmugasundaram, P., \& Babu, R. C. (2005). Identification of microsatellite marker associated with drought tolerance in rice (Oryza sativa L.) using bulked line analysis. Tropical Agricultural Research $17,39-47$.

Le, T. X., \& Tran, D. N. (2013). Selecting rice varieties tolerant to salinity in the Mekong Delta of Vietnam. Can Tho University Journal of Science 28b, 79-85.

Manickavelu, A., Nadarajan. N., Ganesh, S. K., Gnanamalar, R. P., \& Chandra, R. B. (2006). Drought tolerance in rice: morphological and molecular genetic consideration. Journal of Plant Growth Regulation $50,121-138$.
Munns R. (2002). Comparative physiology of salt and water strees. Plant, Cell and Environment 25(2), 239250 .

Nguyen, C. H., \& Huynh, T. Q. (1999). Evaluation of upland rice cooperation in mountainous areas of Vietnam. Scientific Conference of Institute of Cultivation Systems (27-32). Can Tho, Vietnam: Can Tho University Publishing House.

Nguyen, D. (2016). Damage more than 5,500 billion VND due to drought, saline intrusion. Retrieved July 19, 2018, from https://dantri.com.vn/xa-hoi/thiethai-hon-5500-ty-dong-do-han-han-xam-nhap-man20160429152416285.htm.

Nguyen, L. T., \& Bui, B. C. (2008). Fine mapping for drought tolerance in rice (Oryza sativa L.). Omonrice 16, 9-15.

Ong, A. H. N., Le, D. V., \& Huynh, T. Q. (2004). Studies on drought tolerance of the central Vietnam upland rice collection based on morphological traits and DNA analysis. Can Tho University Journal of Science 1, $130-136$.

Rogers, S. O., \& Bendich, A. J. (1988). Extraction of DNA from plant tissues. In Gelvin, S. B., Schilperoort, R. A., \& Verma, D. P. S. (Eds.). Plant molecular biology manual 6 (1-11). Kluwer Academic Publishers: Dordrecht, The Netherlands.

Sumontip, B., \& Prapaporn, P. (2013). Selection of rice (Oryza sativa L.) cultivars tolerant to drought stress at the vegetative stage under field condition. American Journal of Plant Science 4, 1701-1708. 